\title{
EFFECT OF LIGHT CURING MODES AND ETHANOL IMMERSION MEDIA ON THE SUSCEPTIBILITY OF A MICROHYBRID COMPOSITE RESIN TO STAINING
}

Flávio Henrique Baggio AGUIAR ${ }^{1}$, Thalita Regina Vieira e OLIVEIRA², Débora Alves Nunes Leite LIMA³, Luis Alexandre Maffei Sartini PAULILLO ${ }^{4}$, José Roberto LOVADINO ${ }^{4}$

\author{
1- DDS, MS, PhD, Assistant Professor, Department of Restorative Dentistry, Piracicaba School of Dentistry - Campinas State University, SP, \\ Brazil. \\ 2- DDS, Undergraduate student, Department of Restorative Dentistry, Piracicaba School of Dentistry - Campinas State University, SP, Brazil. \\ 3- DDS, MS, PhD student, Department of Restorative Dentistry, Piracicaba School of Dentistry - Campinas State University, SP, Brazil. \\ 4- DDS, MS, PhD, Full Professor, Department of Restorative Dentistry, Piracicaba School of Dentistry - Campinas State University, SP, Brazil. \\ Corresponding address: Dr. Flávio Henrique Baggio Aguiar - Department of Restorative Dentistry - Piracicaba School of Dentistry - \\ Campinas State University - Av. Limeira, 901 - Piracicaba / SP - Brazil - 13414-903 - Phone: 551921065340 - Fax: 551934210144 - e-mail: \\ aguiar@fop.unicamp.br
}

Received: June 1, 2006 - Modification: November 23, 2006 - Accepted: March 16, 2007

\begin{abstract}
$T_{\text {he }}$

The aim of this in vitro study was to evaluate the susceptibility of a hybrid composite resin (Filtek Z250 - 3M ESPE) to staining, when light cured in four different modes and immersed in two different media. Composite resin specimens were randomly prepared and polymerized according to the experimental groups (conventional $-550 \mathrm{~mW} / \mathrm{cm}^{2} / 30$ seconds; soft start $-300 \mathrm{~mW} / \mathrm{cm}^{2} / 10$ seconds $+550 \mathrm{~mW} / \mathrm{cm}^{2} / 20$ seconds; high intensity $-1060 \mathrm{~mW} / \mathrm{cm}^{2}-10$ seconds; pulse delay $-550 \mathrm{~mW} / \mathrm{cm}^{2}$ -1 seconds +60 seconds of waiting time $+550 \mathrm{~mW} / \mathrm{cm}^{2}-20$ seconds) and immersed in one of two media (distilled water or absolute ethanol) for $24 \mathrm{~h}$. Next, the specimens were immersed in a $2 \%$ methylene blue solution for 12 hours. Afterwards, the specimens were washed and prepared for the spectrophotometric analysis. For statistical analysis, two-way ANOVA (4X2) and Tukey's test were performed on the data at 0.05 confidence level. Soft start showed the least staining, and was statistically different from the high intensity and pulse delay light curing modes $(\mathrm{p}<0.05)$. Conventional light curing unit did not show statistically significant differences from any other groups $(\mathrm{p}>0.05)$. There were no significant differences between the two immersion media $(\mathrm{p}>0.05)$. The soft start polymerization mode showed lower susceptibly of the composite resin to staining than high intensity and pulse delay, irrespective of the immersion medium.
\end{abstract}

Uniterms: Light-curing modes; Composite resins; Staining; Storage media.

\section{INTRODUCTION}

Dental composite resin is the most frequently used direct tooth-colored restorative material ${ }^{4}$. Improvements in composite mechanical properties have made them more reliable for use in posterior teeth than they were some years $\operatorname{ago}^{14,17}$. However, a high degree of polymerization means high polymerization shrinkage. The development of shrinkage during polymerization is the major disadvantage of light cured composites and compomers ${ }^{13,16}$. The conversion of the monomer molecules into a polymer network is accompanied by a closer packing of the molecules, causing contraction in the composite ${ }^{9,10}$. This contraction creates mechanical stresses in the resin composite, which can disrupt the marginal seal between the composite restoration and dentin or enamel ${ }^{9}$. Polymerization shrinkage leads to several clinical problems, such as marginal discoloration, restoration fractures, solubility of the bonding system and marginal leakage ${ }^{12}$.

There are three phases in polymerization shrinkage: the pre-gel, gel point and post gel phase, but the only one capable of disrupting the marginal seal between the composite restoration and dentin/enamel is the post-gel phase $^{10,12}$. This occurs because, in the phase before the gel point, the monomers can still move or slip into new positions within the resin matrix, without causing stress at the interface ${ }^{12}$. As the number of monomers converted into polymers increases, the flow gradually decreases, while the resin composite becomes stiffer and the material becomes strong enough to exert forces or stress in the bond system $^{9,10}$. Post gel polymerization results in clinically significant stress in the composite-tooth bond and surrounding tooth structure ${ }^{24}$, leading to adhesion failure ${ }^{12}$.

Adhesive bond strength, restorative material elastic 
modulus, cavity design, light intensity and curing time are some of the factors influencing the marginal quality of restorations ${ }^{10,23}$. A number of polymerization techniques have been developed in an attempt to reduce the stress caused by polymerization shrinkage. Initial polymerization with low intensity light followed by final cure with high intensity light may result in improved marginal integrity without losing the achievable material properties ${ }^{19}$. The aim of the technique using low light curing intensity is to prolong the time span before gel point is reached and to increase the material flow capability. Afterwards, high light intensity is necessary to achieve complete polymerization and optimal mechanical properties ${ }^{10}$. Another technique that prolongs the time span before reaching gel point, similar to the soft start method, is the pulse activation technique ${ }^{16}$. It differs from the soft start, as there is a waiting interval between the initial low intensity and the final exposure to the high intensity light. Several studies ${ }^{1,21}$ have investigated the pulse delay technique and the general consensus is that it reduces polymerization shrinkage stress without decreasing mechanical properties. However, these two techniques have long cure times, which are inconvenient for the patient, impractical with children, uncomfortable for the dentist and make the treatment more expensive because of the extra time spent in the chair ${ }^{20}$.

A different method of providing extremely high irradiance levels is to use curing units that emit high intensity light, as they allow resin composite polymerization to occur very quickly and are recommended because of the curing depth and mechanical properties achieved. High light curing, which is compensated by the intensity, can polymerize the resin composite in a shorter time. However, these high light intensities do not allow enough flow for reducing internal stress, thus contribute to high polymerization shrinkage ${ }^{3,19}$, and increased leakage ${ }^{3}$.

Different polymerization modes can lead to the resulting polymer having different structures, even though the degree of monomer conversion is the same ${ }^{6}$. Thus, some physical properties, like hardness, diametral tensile strength and wear resistance show differences ${ }^{15,18}$. The differences among the physical properties of composite resin cured with different polymerization systems has been shown to be more evident when this material was immersed in ethanol ${ }^{6,18}$. Ethanol causes the resin composite surface to soften, by removing the polymer structure, such as unreacted monomer, oligomers and linear polymers ${ }^{6}$ or imparting an opener structure to the polymer, facilitating the sorption of pigment agents and increasing wear ${ }^{5,18,22}$.
Asmussen and Hansen ${ }^{5}$ (1986) studied the relation between composite resin surface softening and discoloration, and concluded that the softening effect on a composite resin surface can increase its susceptibility to staining. Material color stability over the time is an important factor in the success of an esthetic restoration ${ }^{19}$. An unacceptable color match is one of major reasons for composite restoration replacement. Thus, this study investigated the effect of different polymerization modes and ethanol immersion on the composite resin susceptibility to staining. The null hypotheses to be tested were: (1) there is no difference in the susceptibility to staining of composite resin light-cured by different polymerization modes; (2) specimens immersed in water or ethanol present no difference in the susceptibility to staining.

\section{MATERIALAND METHODS}

A hybrid composite resin Filtek Z250 (3M-ESPE Dental Products, St. Paul, MN, USA) was used in this study. Forty cylindrical specimens were prepared using Teflon ring moulds ( $5.0 \mathrm{~mm}$ in internal diameter and $2.0 \mathrm{~mm}$ depth) held between two glass slabs separated by milar matrix strips, and then pressed with a $500 \mathrm{~g}$ load. The cavity was filled in one increment and was randomly polymerized according to the four experimental light curing mode groups (Table 1). The initial intensity of soft start group was obtained by polymerization with the light tip at a distance of $0.9 \mathrm{~cm}$ from the composite resin top surface (controlled by an electronic digital caliper).

Specimens were stored in distilled water at $37^{\circ} \mathrm{C}$ for 24 hours and the top surface of each specimen was polished with flexible aluminum oxide disks (Sof-Lex Pop-on ${ }^{\circledR}$ - 3M ESPE) under water spray. All specimens were randomly assigned to one of the two media (distilled water or absolute ethanol) at $37^{\circ} \mathrm{C}$ for 24 hours. After this period, the specimens were washed in tap water, immersed separately in $4 \mathrm{~mL}$ of $2 \%$ methylene blue solution for 12 hours at $37^{\circ} \mathrm{C}$ and thereafter, rinsed in tap water and air-dried.

Each specimen was weighed and ground into powder in a hard tissue mill (Marconi Equip. Ltda, Piracicaba, SP, Brazil). The resulting powder was weighed, and, if the difference between the initial and final weight was greater than $10 \%$, the specimen should be discarded. In this study, no specimens were discarded. The powder from each specimen was immersed for 24 hours in a glass tube containing $4 \mathrm{~mL}$ of absolute alcohol PA in order to dilute the methylene blue.

TABLE 1- Experimental groups (light curing modes)

Experimental Groups

Conventional

Soft Start

High Intensity

Pulse Delay

Light Curing Intensity

Light Curing Unit

$550 \mathrm{~mW} / \mathrm{cm}^{2} / 30 \mathrm{~s}$

$300 \mathrm{~mW} / \mathrm{cm}^{2} / 10 \mathrm{~s}+550 \mathrm{~mW} / \mathrm{cm}^{2} / 20 \mathrm{~s}$

$1060 \mathrm{~mW} / \mathrm{cm}^{2}-10 \mathrm{~s}$

$550 \mathrm{~mW} / \mathrm{cm}^{2}-1 \mathrm{~s}+60 \mathrm{~s}$ of waiting time $+550 \mathrm{~mW} / \mathrm{cm}^{2}-20 \mathrm{~s}$
XL 3000 - 3M Espe

XL 3000 - 3M Espe

Optilux 501C - Demetron

XL 3000 - 3M Espe 
Next, the solutions were centrifuged (Tomy -IC 15AN Tomy Ind., Tokyo, Japan) at $3000 \mathrm{rpm}$ for 3 minutes. The supernatant (floating solution) was analyzed with a spectrophotometer (Beckman DU-65 - Instruments, Inc., Fullerton, CA, USA) adjusted to a measurement wavelength of $668 \mathrm{~nm}$.

To calibrate the spectrophotometer, the absorbance of the standard solutions $(0.1 ; 0.2 ; 0.3 ; 0.5 ; 1 ; 2 ; 4 ; 6 \mu \mathrm{g} / \mathrm{mL})$ was determined at wavelengths ranging from 400 to $700 \mathrm{~nm}$, and the maximum value was obtained at $668 \mathrm{~nm}$. At this wavelength, the absorbencies for the standard solutions were obtained. With these values, a coefficient of linear correlation $(\mathrm{r}=0.9998)$ and a straight-line equation $(\mathrm{y}=\mathrm{a}+$ bx) were determined. The following relation was obtained: Absorbance $=0.2716 \times$ (dye concentration) -0.0075 . To calculate the quantity of the dye concentration $(\mathrm{mg} / \mathrm{mL})$ in the experimental samples, the "y" was changed fo the absorbency value of each specimen.

For statistical analyses, two-way ANOVA and Tukey's test were performed on the data at 0.05 confidence level. The values presented normal and homogeneous distribution. The Shapiro-Wilk's test (test for normality) $(p>0.05)$ confirmed the normality and homoscedasticity of the groups.

\section{RESULTS}

Results of the staining test are presented on Table 2 .
ANOVA (Table 3) showed no statistically significant differences $(\mathrm{p}>0.05)$ between the two immersion media. There were statistically significant differences $(\mathrm{p}<0.05)$ among the four polymerization modes. The Tukey's test was applied to individual comparisons and showed that the soft start polymerization mode had the lowest staining means, significantly different from the high intensity and pulsedelay curing modes $(\mathrm{p}<0.05)$. The conventional polymerization mode did not present statistically significant differences from any other polymerization mode $(p>0.05)$ (Table 2).

\section{DISCUSSION}

An important factor in the success of an esthetic restoration is the material color stability over time ${ }^{8}$. The susceptibility of a resin composite to staining may, subject to several factors, be associated with the polymerization mode. Under the experimental conditions of this study, the results showed that different polymerization methods can alter composite resin susceptibility to staining. Thus, the first null hypothesis was rejected. In relation to the immersion media, there was no statistically significant difference between water and ethanol media. Thus, the second null hypothesis was accepted.

Resin discoloration may be associated with its affinity for stains and water sorption due to its lower monomer conversion degree ${ }^{7}$. Water sorption is associated with

TABLE 2- Results of staining means for the experimental groups (light curing modes) $(\mu \mathrm{g} / \mathrm{mL})$. Means with the same lowercase letter were not statistically different $(p<0.05)$ for comparisons between the same medium. Means with the same uppercase letter were not statistically significant different $(p<0.05)$ for comparisons between the same polymerization mode

\begin{tabular}{lll} 
Experimental Groups & Water Media & Ethanol media \\
\hline Conventional & $0,356 \mathrm{~A} \mathrm{ab}$ & $0,372 \mathrm{~A} \mathrm{ab}$ \\
Soft Start & $0,290 \mathrm{~A} \mathrm{a}$ & $0,350 \mathrm{Aa}$ \\
High Intensity & $0,424 \mathrm{~A} \mathrm{~b}$ & $0,408 \mathrm{Ab}$ \\
Pulse Delay & $0,394 \mathrm{Ab}$ & $0,422 \mathrm{Ab}$ \\
\hline
\end{tabular}

TABLE 3- Results of 2-way ANOVA

\begin{tabular}{|c|c|c|c|c|}
\hline Source of variation & DF & SQ & MQ & $\mathbf{F}$ \\
\hline Light curing modes (LCM) & 3 & .0006 & .0002 & 3.9330 * \\
\hline Immersion media (IM) & 1 & .0000 & .0000 & $.8911 \mathrm{NS}$ \\
\hline LCMXIM & 3 & .0001 & .0000 & .4472 NS \\
\hline Treatments & 7 & .0007 & .0001 & \\
\hline Error & 32 & .0015 & .0015 & \\
\hline
\end{tabular}

DF - degree of freedom; SQ - Sum of squares; MQ - Mean square; * - statistically significant difference; NS - no statistically significant difference. 
polymer degradation, and can also be associated with the type of polymer ${ }^{11}$. Asmussen and Petutzfeldt ${ }^{6}(2001)$ reported that light intensity and polymerization time can modify polymer structure formation. Polymerization with pulse delay causes little growth at the centre of the polymer and, consequently, propagation will predominantly add one molecule of monomer after another to a growing polymer chain. This results in a more linear oligomer or polymer structure with relatively few cross-links. The final cure will activate a large part of the remaining camphoroquinone and thus give rise to a multitude of growth centers that will increase the tendency to form a branched polymer. The authors of the above-mentioned study credit the polymer structures formed with the pulse delay technique to the softness of the surface after being immersed in ethanol. This polymer structure may be associated with a greater sorption of liquid, resulting in more susceptibility to staining. The results of the present study corroborate with this statement.

The high intensity polymerization mode did not show significant differences from pulse delay and conventional polymerization. Initial high intensity develops higher polymerization shrinkage stress due the rapid and immediate polymerization reaction. A high initial intensity can result in a polymer structure with higher cross-link density, due the large amount of monomer that reacts, generating several growth centers. However, a supposition for the high susceptibility to staining of this polymerization mode is that 10 seconds of polymerization are not sufficient for an effective cure at a deeper layer of the sample. Aguiar, et al. ${ }^{1}$ (2005) showed that reduced polymerization times at high intensity provide an unsatisfactory cure at the deepest layer of the composite resin, and this under-cured layer is more susceptible to staining.

The Soft Start technique showed less susceptibility to staining and it did not show statistically significant differences from conventional technique. Asmussen and Petutzfeldt ${ }^{6}$ (2001) reported that conventional polymerization with a continuous intensity will initiate a multitude of growth centers, resulting in a polymer structure with higher crosslink density. It may be compared with a ladder in which each original monomer molecule represents a step. In the abovementioned study, the intensity for the conventional technique was $450 \mathrm{~mW} / \mathrm{cm}^{2}$. In the soft start groups of the present study, the initial intensity was $300 \mathrm{~mW} / \mathrm{cm}^{2}$, which is a value close to the one used in Asmussen's study ${ }^{6}$. Based on these values, it can be supposed that both soft start groups and conventional groups $\left(550 \mathrm{~mW} / \mathrm{cm}^{2}\right)$ had comparable polymer structures and showed an equivalent behavior regarding to the susceptibility to staining. However, the conventional technique presented an intermediate behavior, and showed no statistically significant differences from either pulse delay and high intensity, or the soft start group. The intermediate intensity may explain these results.

Another theory studied concerned the immersion medium. It was tested water and ethanol. Ethanol simulates certain beverages and alcoholic drinks, and distilled water simulates the wet intra-oral environment provided by saliva and water. It was expected that the ethanol medium could increase the resin composite susceptibility to staining. Ethanol causes resin composite surface to soften, by removing the polymer structure such as unreacted monomer, oligomers and linear polymers ${ }^{6}$, or imparting a opener structure to the polymer, thereby facilitating the sorption of pigment agents and increasing wear ${ }^{5,18,22}$. In a composite resin with the same degree of monomer conversion, it may be that dissolution by ethanol is more selective in a relatively linear polymer than in one that is expected to have a more cross-linked structure. However, ethanol did not increase the susceptibility to staining for any polymerization mode. In other studies that associated softening agents with staining, the pigment agent was associated with the softening agent $t^{5,18,22}$. Aguiar, et al. ${ }^{2}$ (2004) used alcoholic and aqueous staining solutions to test susceptibility of colored restorative materials to staining, and concluded that alcoholic solutions had higher staining means than aqueous ones. In the mentioned studies, the pigment penetrated at the same time as the ethanol altered the polymeric matrix. In the present study, ethanol was first applied to the resin composite and then the pigment agent was applied. It is possible that ethanol removed the organic matrix responsible for absorbing the pigment, thus not interfering in the staining.

In vivo studies must been done to confirm the relation of composite polymerization and staining susceptibility. It is difficult to establish a direct relation between in vitro and in vivo outcomes. However, in vitro studies may guide one to conclusions that can be later confirmed in vivo and then improves the clinical activity. Further studies must also been done with another dyes associated with dietary habits, such as consumption of coffee, soft drinks, alcoholic drinks and others.

\section{CONCLUSION}

Within the limits of this study, it may be concluded that:

1. The ability of a composite resin surface to be stained was not related to the two immersion media studied;

2. The mode of polymerization can affect the staining of composite resin restorations;

3. The soft start polymerization mode resulted in the lowest staining for the composite resin evaluated, statistically different from high intensity and pulse delay, and similar to conventional light curing mode.

\section{ACKNOWLEDGMENTS}

This study was supported by a grant-in-aid from FAEPUNICAMP 


\section{REFERENCES}

1- Aguiar FHB, Braceiro ATB, Ambrosano GMB, Lovadino JR. Hardness and diametral tensile strength of a hybrid composite resin polymerized with different modes and immersed in ethanol or distilled water media. Dent Mater. 2005;21:1098-103.

2- Aguiar FHB, Santos AJS, Sad LO, Lovadino JR Surface Staining of three restorative materials by two disclosing agents. RPG Rev Posgrad. 2004;11:215-9.

3- Althoff O, Hartung M. Advances in light curing. Am J Dent. $2000 ; 13: 77-81$

4- Applequist EA, Meiers JC. Effect of bulk insertion, prepolymerized resin composite balls, and beta-quartz inserts on microleakage of class V resin composite restorations. Oper Dent. 1996;27:253-8.

5- Asmussen E, Hansen EK. Surface discoloration of restorative resins in relation to surface softening and oral hygiene. Scand J Dent Res. 1986;94:174-7.

6- Asmussen E, Peutzfeldt A. Influence of pulse-delay curing on softening of polymer structures. J Dent Res. 2001;80:570-3.

7- Dietschi D, Campanile G, Holz J, Meyer JM. Comparison of the color stability on ten new-generation composites: an in vitro study. Dent Mater. 1994;10:353-62.

8- Fay RM, Walker CS, Power JM. Color stability of hybrid ionomers after immersion stains. Am J Dent. 1998;11:71-2.

9- Feilzer AJ, de Gee AJ, Davidson CL. Quantitative determination of stress reduction by flow in composite restorations. Dent Mater. 1990;6:167-71

10 - Friedl KH, Schmalz G, Hiller KA, Märkl A. Marginal adaptation of class $\mathrm{V}$ restorations with and without softstart-polymerization. Oper Dent. 2000;25:26-32.

11 - Göpferich A. Mechanisms of polymer degradation and erosion. Biomaterials. 1996;17:103-14.

12- Koran P, Kürschner R. Effect of sequential versus continuous irradiation of a light-cured resin composite on shrinkage, viscosity, adhesion, and degree of polymerization. Am J Dent. 1998;10:17-22.

13- Lambrechts P, Braem M, Vanherle G. Evaluation of clinical performance for posterior composite resins and dentin adhesives. Oper Dent. 1987;12:53-78

14- Leinfelder KF, Bayne SC, Swift EJ Jr. Packable composites: overview and technical considerations. J Esthet Dent. 1999;11:23449

15 - Lim B, Ferracane JL, Condon JR, Adey JD. Effect of filler fraction and filler surface treatment on wear of microfilled composites. Dent Mater. 2002;18:1-11.

16- Luo Y, Lo EC, Wei SH, Tay FR. Comparison of pulse activation vs. conventional light-curing on marginal adaptation of a compomer conditioned using a total-etch or a self-etch technique. Dent Mater. 2002; $18: 36-48$

17- Manhart J, Kunzelmann KH, Chen HY, Hickel R. Mechanical properties and wear behavior of light-cured packable composite resins. Dent Mater. 2000;16:33-40.

18- McKinney JE, Wu W. Chemical softening and wear of dental composites. J Dent Res. 1985;64:1326-31.
19- Mehl A, Hickel R, Kunzelmann KH. Physical properties and gap formation of light-cured composites with and without softstartpolymerization. Oper Dent. 1997;25:321-30.

20- Peutzfeldt A, Sahafi A, Asmussen E. Characterization of resin composites polymerized with plasma arc curing units. Dent Mater. 2000;16:330-6.

21- Pfeifer CS, Braga RR, Ferracane JL. Pulse delay curing: influence of initial irradiance and delay time on shrinkage stress and microhardness of restorative composites. Oper Dent. 2006;31:610-

22- Sarret DC, Coletti DP, Peluso AR. The effects of alcoholic beverages on composite wear. Dent Mater. 2000;16:62-7.

23 - Unterbrink GL, Muessner R. Influence of light intensity on two restorative systems. J Dent.1995;23:183-9.

24- Yap AUJ. Effectiveness of polymerization in composite restoratives claiming bulk placement: impact of cavity depth and exposure time. Oper Dent. 2000;25:113-20. 